\title{
Arbor
}

\section{El enigma de la religión}

\section{Antonio Campillo Meseguer}

Arbor CLXXI, 676 (Abril), 637-651 pp.

a José Joaquín Alemany, in memoriam

Una reflexión filosófica sobre la experiencia humana del mundo, sobre sus condiciones universales y sobre sus variaciones históricas, no puede dejar de responder a estas tres preguntas entrelazadas: ¿qué es eso a lo que llamamos religión? ¿es algo inherente a la experiencia humana del mundo? ¿cuáles han sido sus variaciones históricas? Tras una relectura de los grandes críticos de la religión (Marx, Nietzsche y Freud), ésta es redefinida como una dimensión universal de la vida humana, que cumple una triple función cultural: articular y legitimar las tres relaciones sociales básicas (el parentesco, la economía y la política), invertir o trascender esas tres relaciones profanas (instituyendo de este modo el orden de lo sagrado) y componer conjuntamente el lado profano y el lado sagrado de la experiencia humana (proporcionando así un mundo simbólicamente compartido y una determinada orientación existencial). Finalmente, el artículo concluye distinguiendo cuatro grandes tipos de religiones: las mitológicas, las teológicas, la moderna religión tecnológica y la post moderna religión ecológica.

No es fácil pensar la religión. No es fácil hacerlo con toda la franqueza y todo el rigor que el ejercicio del pensamiento exige de nosotros. Lo más frecuente es que sigamos uno de estos dos falsos atajos: por un lado, el atajo de pensar sobre (o ante) la religión, como si sólo se tratase de un hecho objetivo, externo y ajeno a nosotros, del que podemos ocuparnos con una atenta y amable curiosidad, pero del que podemos igualmente despreocuparnos con una distante y despectiva indiferencia; por otro 
lado, el atajo de pensar bajo (o desde) la religión, como si sólo se tratase de una vivencia subjetiva, tan íntima y tan propia que nos posee y nos constituye por entero, hasta el punto de convertirse en nuestra última e inapelable fuente de autoridad. En ambos casos, sea que hagamos de ella el objeto o el sujeto de nuestra palabra, estamos dando por supuesto que ya sabemos lo que es la religión: ya sabemos dónde, cuándo y cómo se manifiesta, puesto que hemos trazado el límite que la delimita y hemos determinado si estamos fuera o dentro de ella, si somos nosotros los que hablamos de ella o es ella la que habla en nosotros. Así que, antes de empezar a pensar, ya está todo sabido y decidido. Por eso son atajos, porque nos ahorran el incierto e inquietante ejercicio del pensamiento.

El ejercicio del pensamiento nos sitúa, por el contrario, en un inhóspito no-lugar en el que nada está sabido ni decidido de antemano, en una tierra de nadie en la que todas las definiciones y delimitaciones son dudosas e inestables, en un desierto sin caminos en el que el horizonte de lo humanamente pensable se desplaza a medida que se desplaza el ejercicio mismo del pensamiento.

Para pensar la religión, sin atajos de ningún tipo, hemos de hacerlo en el marco de una reflexión filosófica más general sobre la experiencia humana del mundo, sobre sus condiciones universales y sobre sus variaciones históricas. Y, a la inversa, una reflexión filosófica sobre las condiciones universales de la vida humana y sobre sus variaciones espacio-temporales, no puede dejar de plantearse la pregunta por la religión. $\mathrm{O}$, más exactamente, no puede dejar de plantearse tres preguntas a un tiempo: primero, ¿qué es eso a lo que damos el nombre de religión?; segundo, ¿es algo inherente a la experiencia humana del mundo?; tercero, ¿cuáles han sido sus grandes variaciones o manifestaciones históricas? Antes de intentar responder a estas preguntas, y precisamente para poder responderlas, describiré brevemente el horizonte de pensamiento en el que creo que nos encontramos situados los humanos de comienzos del siglo XXI ${ }^{1}$.

Nuestra condición humana es constitutivamente paradójica: por un lado, formamos parte del mundo que nos rodea, estamos hechos de la misma sustancia que el resto de los seres y dependemos de ellos para seguir siendo lo que somos, de modo que mantenemos con ellos un parentesco originario, una imborrable identidad ontológica; por otro lado, nos separamos radicalmente de todos los otros seres y nos oponemos frontalmente a ellos desde el momento en que decimos «nosotros» y nos autoafirmamos como humanos frente al mundo no humano, instituyendo así una extrañeza igualmente originaria, una diferencia ontológica igualmente imborrable. Lo humano de la condición humana tiene, pues, una doble cara: es algo que recibimos pasivamente y algo que recreamos acti- 


\section{El enigma de la religión}

vamente, es una realidad objetivamente dada y una posibilidad subjetivamente instituida, es un qué susceptible de conocimiento científico y de manipulación técnica, pero es también un quién susceptible de reconocimiento político y de responsabilidad ética. Como en la cinta de Moebius, que tiene a la vez dos caras y una sola cara, los dos lados de lo humano son a la vez irreductibles e inseparables entre sí.

Esta irresoluble paradoja nos permite comprender por qué lo humano de la condición humana no es una esencia eterna, estable y universal, dada de una vez por todas y para siempre, sino una existencia histórica, cambiante y plural, que ha venido experimentando incesantes variaciones espacio-temporales. En efecto, la condición humana es constitutivamente histórica, entendiendo esta historicidad como una relación de mutua e incesante remisión entre los seres humanos singulares y el mundo igualmente singular en el que habitan, es decir, como una reversión sin fin entre el lado «subjetivo» y el lado «objetivo» de la experiencia humana del mundo. Esta remisión recíproca entre lo humano y lo mundano se rige por el principio ontológico de la variación espacio-temporal, que postula la diversificación inagotable y la mutación imprevisible de todo cuanto acontece.

Ahora bien, no es posible dar cuenta de la diversidad de la experiencia humana sin intentar determinar qué hay de humano, y, por tanto, de común o de comunicable, en esa diversidad. ¿Qué es lo que nos permite reconocernos unos a otros como humanos y decir «nosotros», a pesar de las profundas e imborrables diferencias que separan nuestras diversas condiciones históricas de vida? ¿Por qué, a pesar de enfrentarnos unos a otros hasta el punto de la mutua negación y el mutuo exterminio, lo hacemos siempre en nombre de una cierta idea y un cierto ideal de humanidad? La experiencia histórica nos dice que la posible comunidad o comunicabilidad entre las diversas formas de lo humano no puede fundarse en una supuesta unidad o identidad dada a priori, ni tampoco puede postularse como la meta de un proceso teleológico ya sabido de antemano y que habrá de conducirnos de forma inexorable a un definitivo "final de la historia», sino que más bien hemos de suponerla como la idea reguladora de una posible relación, en modo alguno segura, entre las diferentes sociedades y los diferentes seres a los que llamamos humanos. La humanidad no es, pues, sino la resultante de la relación entre las diferentes manifestaciones de lo humano. Pero, mientras sigan viniendo al mundo nuevos seres humanos, esas diferentes manifestaciones seguirán proliferando, de modo que la resultante nunca podrá ser definitiva ni definitoria.

Teniendo en cuenta la historia de las sociedades humanas hasta ahora conocidas, es posible discernir unos cuantos rasgos comunes que se re- 
piten en todas ellas, aunque de forma siempre diferente. Ante todo, la vida humana es una vida eminentemente social, plural, intersubjetiva, formada por un complejo y cambiante entramado de relaciones más o menos institucionalizadas, a un tiempo conflictivas $y$ comunicativas. Además, todas las sociedades humanas hasta ahora conocidas cuentan con tres tipos de relaciones sociales (económicas, parentales y politicas) que se encuentran fuertemente institucionalizadas, porque responden a tres condiciones naturales de la vida humana: la supervivencia orgánica, la reproducción sexual y los conflictos inherentes a una pluralidad de individuos y de grupos que conviven en un mismo territorio.

Por medio de estas tres relaciones sociales, los seres humanos instituimos nuestra humanidad, esto es, nos autoafirmamos y nos reconocemos unos a otros como sujetos humanos. En efecto, el proceso de subjetivación o de autoafirmación de lo humano tiene lugar a través de una triple diferenciación: la diferencia sujeto-objeto, que funda las relaciones económicas; la diferencia yo-tú, que funda las relaciones parentales; y la diferencia nosotros-los otros, que funda las relaciones políticas.

Estas tres relaciones sociales son irreductibles e inseparables entre sí, de modo que no cabe establecer entre ellas una relación de jerarquía, es decir, de derivación y dependencia unilateral, sino más bien una relación de mutua tensión y mutua dependencia. No cabe conceder a una sola de estas relaciones sociales la primacía absoluta en la configuración de la sociabilidad humana, como han pretendido muchos teóricos de la sociedad. Así, Smith y Marx concedieron ese privilegio a la economía, Freud y Lévi-Strauss se lo concedieron al parentesco, mientras que Hobbes y Schmitt se lo concedieron a la política. Sin embargo, lo cierto es que cada una de ellas hace posible el tránsito y la simbiosis entre la naturaleza y la cultura, entre la animalidad y la humanidad, entre el lado objetivo y el lado subjetivo de la experiencia humana del mundo, de modo que no es posible hablar de una sociedad humana sin la presencia simultánea e inseparable de estas tres formas de relación social.

Ahora bien, estas tres relaciones sociales se han ido articulando entre sí de muy diversas maneras según los tiempos y los lugares, dando origen a un incontable número de variaciones históricas. Siguiendo el procedimiento de los tipos ideales propuesto por Weber y Durkheim, es posible agrupar todas esas variaciones en cuatro grandes tipos históricos: las sociedades tribales, las sociedades estamentales, la moderna sociedad capitalista y la naciente sociedad global. Esta tipología nos permite llevar a cabo una nueva interpretación de la historia, que no estaría ya basada en la moderna idea de evolución sino en la posmoderna idea de variación. 


\section{El enigma de la religión}

Creo que ahora ya estamos en condiciones de enfrentarnos a los grandes interrogantes que la religión nos plantea. Todas las sociedades cuentan con tres relaciones sociales básicas (económicas, parentales y políticas), con las que tratan de responder a tres diferentes necesidades o condiciones «naturales» de la vida humana: la supervivencia, la procreación y la rivalidad; de modo que no parece posible la vida humana, en cuanto vida social o «cultural», si no es en el marco de estos tres tipos de relaciones. Ahora bien, ¿tiene la religión este mismo carácter universal? Es decir, ¿constituye una cuarta condición de la vida humana, de modo que la vida humana, en cuanto vida social, no sería posible sin ella? Y, si así fuera, ¿a qué necesidad «natural» respondería? Más aún, ¿qué respuesta «cultural» y qué relación social podrían ser consideradas como específicamente religiosas? Por último, ¿cuáles serían sus principales variaciones históricas?

Para responder a todas estas preguntas, habría que comenzar por definir el concepto mismo de religión. Habría que plantearse si es posible dar cuenta de las más diversas creencias y prácticas religiosas, desde los mitos y ritos tribales hasta las grandes «religiones de salvación», a partir de un único concepto de religión. Así como lo político es un campo de relaciones sociales que está presente en todas las sociedades, y que por tanto no puede ser identificado con una forma cultural determinada (como es el caso del Estado, que sólo aparece en algunas sociedades, y sólo en un momento histórico relativamente tardío), habría que plantearse si es posible definir el campo de lo religioso sin identificarlo con formas culturales aparecidas sólo en algunas sociedades a partir de un determinado momento de su historia (como es el caso de las citadas «religiones de salvación", contemporáneas de los primeros grandes Estados). Más aún, esa definición de lo religioso, para ser universalizable, debería dar cuenta del proceso de «secularización» seguido por el Occidente moderno y de la pretendida desaparición o «superación» histórica de las formas religiosas tradicionales.

De no ser posible tal concepto, la religión no podría ser considerada como esencial a la condición humana, sino simplemente como una forma cultural característica de determinadas sociedades en un determinado período de su historia. Así, si limitamos el concepto de religión a las grandes «religiones de salvación», como suele ser habitual, quedarían excluidos los relatos míticos y los ritos mágicos (mucho más antiguos y más extendidos que ellas), y quedarían igualmente excluidas las sociedades modernas o «secularizadas", en las que tanto la «magia» como la «religión» habrían sido reemplazadas o marginalizadas por la «racionalidad» (y la mutua autonomía e irreductibilidad) de los saberes científico-técnicos, de las reglas ético-jurídicas y de las creaciones artístico-literarias. 
Desde el evolucionismo del siglo XIX, se han hecho habituales esta clasificación formal y esta periodización histórica: la «magia», la «religión» y la «ciencia» serían tres formas diferentes y sucesivas de pensar el mundo y de regular la acción humana. Todos los grandes críticos de la religión, desde Feuerbach en adelante (pasando por los tres «maestros de la sospecha»: Marx, Nietzsche y Freud), han entendido la religión en este sentido limitado, como una forma histórica pasajera, más aún, como una enfermedad infantil del pensamiento humano, fruto de la explotación económica (Marx), el resentimiento moral (Nietzsche) y la culpa edípica (Freud). Y han considerado que lo propiamente «moderno» de la cultura moderna es el esfuerzo por curarse de tal enfermedad. La "mayoría de edad» de la cultura moderna, su madurez intelectual y moral, su superioridad sobre el resto de las culturas, su legitimidad para afirmarse sobre ellas y guiarlas por el camino del «progreso», se funda precisamente en el supuesto de haber logrado curarse o liberarse de la enfermedad religiosa.

Ahora bien, ¿en qué consiste la enfermedad religiosa para estos críticos? Evidentemente, se trata de una enfermedad mental, que afecta a las capacidades intelectuales y morales del ser humano, a su poder para razonar y decidir por sí mismo acerca de lo verdadero y lo falso, lo bueno y lo malo. Al contraer esta enfermedad, los seres humanos se convierten en unos enajenados. Siguen pensando y actuando, pero lo hacen de forma delirante, ignorándose y contrariándose a sí mismos, contraviniendo las necesidades y posibilidades propias de su condición. Si hemos definido la condición humana como el movimiento de autoafirmación de la subjetividad en el triple dominio económico (sujeto-objeto), parental (yo-tú) y político (nosotros-los otros), la religión vendría a ser la negación de ese triple movimiento, y por tanto la negación de la condición humana en cuanto tal. Por medio de la religión, el ser humano se niega a sí mismo en cuanto sujeto, es decir, en cuanto ser capaz de autoafirmarse frente a los objetos y frente a otros sujetos. La religión, pues, sería esencialmente nihilista.

Pero este nihilismo religioso, según sus críticos, no sólo lleva al ser humano a negar o trascender de forma delirante su propia condición, sino también a atribuírsela a los seres no humanos. Si el viviente humano adquiere su humanidad mediante un triple movimiento de autoafirmación (sujeto-objeto, yo-tú, nosotros-los otros) que da lugar a tres tipos de relaciones sociales (la economía, el parentesco, la política), la religión sería un movimiento de dirección contraria, que engendraría a su vez un nuevo tipo de relación social. La religión hace que los seres humanos alienen su humanidad, su subjetividad, pero esto no sólo significa que renie- 


\section{El enigma de la religión}

gan de ella sino que en el mismo movimiento la proyectan fuera de sí y la transfieren a otros seres (reales o imaginarios), a los que atribuyen sus propias cualidades o capacidades humanas, y con los que pretenden establecer unas relaciones análogas al resto de las relaciones sociales. Mediante esta proyección o transferencia de cualidades y de relaciones, el propio ser humano cree poder proyectarse o trascenderse a sí mismo, cree poder rebasar los límites de su condición específicamente humana. La religión sería, pues, una forma de pensar y de actuar que, lejos de limitarse a configurar «culturalmente» las condiciones «naturales» de la vida humana, trataría de suprimirlas o trascenderlas por completo. La religión sería, en este sentido, una hipertrofia de la cultura.

Ahora bien, ¿cómo es posible que los seres humanos se nieguen a sí mismos y pretendan trascender las condiciones que los constituyen como tales? ¿Cuál es el origen de esta enfermedad mortal que los enajena y que incluso los aniquila? ¿Por qué esta hipertrofia cultural está presente en las más diversas culturas? ¿Por qué la llamada cultura «moderna» es la única que pretende haberse inmunizado contra tal enfermedad? Si la religión es esencialmente la negación de la condición humana, su reiterada presencia en las más diversas sociedades y épocas de la historia humana se convierte en un verdadero enigma.

Los críticos de la religión tienen una respuesta a todas estas preguntas: ha sido la infancia histórica del ser humano, su minoría de edad cultural, es decir, su dependencia real (económica, parental, política) con respecto a otros seres (humanos y no humanos), lo que ha engendrado en él esa negación de sí y esa hipertrofia del poder atribuido a otros seres considerados sobrehumanos. En otras palabras, la religión es explicada a partir de la explotación económica (Marx), la represión patriarcal (Freud) o la dominación política (Nietzsche).

Para estos tres autores, la religión es a la vez una enfermedad mental y una forma de pensamiento infantil, que afecta tanto a la capacidad de conocer y dominar el mundo como a la capacidad de regular las propias relaciones sociales. La religión desorienta al ser humano, lo incapacita para orientarse racionalmente en el mundo y lo pone en manos de otros seres humanos. Por tanto, el viviente humano no adquiere su verdadera humanidad más que a través de un largo proceso de curación y maduración, por el que se afirma a sí mismo como sujeto y niega toda dependencia con respecto a otros sujetos ( $y$, en general, con respecto a todo otro ser). La humanidad plenamente realizada sería, pues, la humanidad liberada del delirio infantil de la religión.

Pueden formularse muchas objeciones a estos grandes críticos de la religión. En primer lugar, ellos suelen tomar como infancia de la huma- 
nidad un período relativamente tardío, en donde ya había clases sociales, familia patriarcal y Estado, pero en las primitivas sociedades tribales no había ninguna de estas tres formas de dominio (económico, parental y político), tal y como han mostrado los más recientes estudios de prehistoria y de antropología social. En segundo lugar, allí donde surgieron tales formas de dominio, las religiones no sólo cumplieron una función de legitimación sino también de subversión o de contestación (como mostró Max Weber en sus estudios de sociología de la religión, y especialmente en sus análisis de las formas «carismáticas» de religiosidad) ${ }^{2}$. En tercer lugar, el ejercicio de la razón (en su triple dimensión cognoscitiva, moral y estética) no se afirmó simplemente frente a la religión, como si ésta fuese un mero obstáculo externo, sino que más bien se desarrolló dentro de ella, en estrecha relación con ella, y la propia historia de las religiones, desde las más antiguas formas del pensamiento mágico, ha de entenderse como el resultado de la creativa y polimorfa racionalidad humana (así lo mostró Weber, una vez más, y así lo ha defendido también la escuela francesa de sociología, desde Durkheim y Mauss hasta Lévi-Strauss) ${ }^{3}$. En cuarto lugar, la específica forma de «racionalidad» que ha caracterizado a la cultura moderna no surgió como una negación sino como una transformación interna de la religión judeo-cristiana (como han señalado, desde diferentes perspectivas, Max Weber, Louis Dumont, Karl Löwith y David F. Noble $)^{4}$. En quinto lugar, las creencias y prácticas religiosas tradicionales no han desaparecido en la época moderna, sino que siguen vigentes en amplios sectores de la población, junto con prácticas y formas de racionalidad secularizadas o desacralizadas; además, han aparecido nuevas formas de religiosidad que pueden ser consideradas como una «resacralización» de prácticas e ideas seculares ${ }^{5}$.

Por último, la llamada «racionalidad» moderna no ha eliminado el dominio entre los seres humanos, ni tampoco les ha asegurado el dominio sobre la naturaleza, sino que ha engendrado nuevas y despiadadas formas de sumisión (como es el caso de los regímenes totalitarios), y ha provocado nuevos y terribles peligros (como es el caso de los peligros ecológicos). La teocracia ha sido sustituida por la tecnocracia, pero eso no significa que el ser humano esté ahora más orientado o menos desorientado que antes; significa que sus criterios de orientación son otros. ¿Habrá que concluir, entonces, que la tecnocracia moderna es la religión de nuestro tiempo, que el mito del progreso es el heredero del mito escatológico judeo-cristiano, y que «mientras no cambien los dioses, nada ha cambiado», como afirma Sánchez Ferlosio?6 ¿Habrá que pensar, como piensa García Calvo, que ser «ateo» no es tan fácil como creían Marx, Freud y Nietzsche, puesto que la creencia científica en un principio últi- 
mo e inapelable de Realidad es equivalente a la creencia religiosa en una Divinidad última e inapelable? ${ }^{7}$.

¿O habrá que pensar, por el contrario, que la religión no es una desviación enfermiza ni una fase infantil del pensamiento humano? Si esa enfermedad se da en todas las culturas y ese infantilismo persiste en todas las épocas, tal vez haya que preguntarse por qué los humanos no somos capaces de curarnos ni de madurar, por qué retorna en nosotros, una y otra vez, ese delirio infantil. Tal vez haya que considerar la religión no ya como una excepción sino como la regla, es decir, como una dimensión constitutiva de la sociedad humana, tal y como defendió Émile Durkheim. Pero, en tal caso, ya no puede ser interpretada de un modo meramente negativo, como el movimiento de alienación de la subjetividad humana; o, en todo caso, ese movimiento de negación tendrá que proporcionar al ser humano algún tipo de positividad, tendrá que permitirle adquirir una forma nueva o suplementaria de subjetividad; de modo que el ser humano no podrá ser comprendido como tal más que a partir de esta duplicación de sí mismo. Esto es lo que propone Durkheim, al recoger de su maestro, Fustel de Coulanges, la distinción ente lo sagrado y lo profano como dos dimensiones irreductibles y complementarias de la experiencia humana.

Pero esto no significa que los análisis críticos de la religión pierdan todo su valor, sino que deben ser reinterpretados. Esos análisis nos han enseñado tres cosas muy importantes. Primero, que la religión tiene que ver con el pensamiento, con la necesidad «natural» que todo ser humano tiene de orientarse en el mundo. Podemos considerar que esta necesidad de orientación es «natural» en la medida en que el ser humano nace desorientado, es decir, en la medida en que cuenta con una escasa determinación genética de su conducta; y la «cultura» no es sino el conjunto de criterios de orientación que le permiten relacionarse con el resto de los seres naturales, con su propio cuerpo y con los otros semejantes a él; de modo que la religión tendría esta positiva y decisiva función «cultural» de orientar al ser humano en su relación (teórica y práctica) con el mundo. Lo que distingue al ser humano no es solamente que regula de forma colectiva su subsistencia, su reproducción y sus conflictos, que somete a reglas el hambre, el sexo y la violencia, sino que, para instituir y articular entre sí esas diversas reglas, se sirve de un lenguaje, más exactamente, de un pensamiento simbólico que comparte con otros y que le permite orientarse en el mundo, que le permite componer con ellos un mundo común, en fin, que le permite comprenderse y conducirse a sí mismo como un ser singular de ese mundo. $\mathrm{Y}$ esa es la función «cultural» que han cumplido todas las religiones. Por eso, no resulta posible separar la 
idea de religión de la idea de cultura. Ésta es la tesis defendida por Thomas Luckmann en La religión invisible ${ }^{8}$.

En una obra anterior, escrita con Peter L. Berger ${ }^{9}$, ambos habían mostrado que la «realidad» es construida socialmente mediante la elaboración de «universos simbólicos», y que son estos universos simbólicos los que permiten al ser humano orientarse en el mundo y adquirir una determinada conciencia de su propia singularidad. En La religión invisible, Luckmann da un paso más y considera que la religión es precisamente ese horizonte último de sentido, que permite al ser humano trascender su mera condición biológica o natural y constituirse como un ser social o cultural. Lejos de identificarla con alguna de sus diversas «formas sociales», Luckmann define la religión como una "condición antropológica» universal, como el distintivo más característico de la vida humana. Desde una perspectiva "materialista», Gustavo Bueno ha defendido una tesis análoga: la aparición de creencias y prácticas religiosas es el «criterio más sólido" para diferenciar a los humanos de los demás animales, por lo que es preciso «tomar a la religión como criterio que marca la transición del protohombre al hombre» ${ }^{10}$.

Una segunda enseñanza puede extraerse de los grandes críticos de la religión: por medio de la religión, el ser humano trata de trascender los límites de su humanidad, tanto los que le han sido «naturalmente» dados como aquellos otros que él mismo ha instituido por medio de las reglas «culturales». ¿Cómo se relaciona esto con lo anterior? Podría decirse que en toda «cultura» humana hay dos aspectos contradictorios entre sí: uno profano y otro sagrado. Por un lado, la cultura es el conjunto de procedimientos profanos o racionales (racionalidad técnica, racionalidad moral, racionalidad estratégica) por medio de los cuales el ser humano afirma su propia subjetividad frente a los otros seres (por la triple vía de la organización laboral, de las coerciones sociales y de las alianzas y rivalidades políticas); pero, por otro lado, esa subjetividad tan dolorosamente adquirida hace de él un esclavo de sus propias restricciones culturales. Por eso, el ser humano no puede dejar de negarse a sí mismo, no puede dejar de trascender sus propios límites, y no puede hacerlo sin relacionarse de un modo diferente -de un modo sagrado- con su propio cuerpo y con el resto de los seres, es decir, sin engendrar nuevas creaciones culturales, nuevas formas de relación social, que dislocan las reglas de su propia racionalidad y ponen en cuestión los límites de su propia humanidad. Ésta es la tesis defendida por Bataille en su Teoría de la religión ${ }^{11}$.

Ahora bien, para hacer compatibles estos dos aspectos contradictorios de la experiencia humana, para que esta disociación no desoriente por completo al hombre, toda «cultura» tiende a componerlos entre sí, tiende 
a integrarlos en un conjunto único. Así se explica la tercera característica de la religión: ésta no se limita a trascender las reglas establecidas por los propios seres humanos en el triple dominio de la economía, el parentesco y la política, sino que simultáneamente viene a darles su más firme fundamento, su más inapelable «legitimidad». Lo sagrado no es sólo lo que se opone a lo profano sino también lo que le sirve de último fundamento «ideológico». Si la religión cumple una positiva y decisiva función «cultural» de orientación de la vida humana, es porque permite al ser humano pensar simultáneamente las dos caras de su propia humanidad. Por eso, no es de extrañar que la religión sea entendida a un tiempo como el movimiento que funda toda idea de Realidad (tal es la interpretación de García Calvo), y como el movimiento que la impugna radicalmente.

Esta última es la definición de religión que nos ofrece Sánchez Ferlosio: «El rechazo del principio de realidad como criterio pertinente para dirimir acerca del bien y el mal del mundo", es decir, el rechazo de todo principio absoluto de orientación en el mundo. No le es esencial a la religión, como ya decían Durkheim y Weber, ni la creencia en dioses ni la esperanza en una vida bienaventurada tras la muerte. Desde este punto de vista, la religión es esencialmente subversiva y a un tiempo esencialmente afirmativa: es la afirmación más extrema del deseo humano de felicidad, es la voluntad insobornable de trascender todo límite, es el rechazo a aceptar justificación alguna para el mal del mundo, es la apuesta por la que el ser humano trata de transformar su propia condición y el estado de cosas del mundo, sin resignarse a acatar una identidad y una realidad dadas. Pero el propio Sánchez Ferlosio reconoce que este movimiento de subversión del principio de realidad se invierte y se integra, en las religiones históricamente constituidas, en un movimiento de restauración y reforzamiento de dicho principio: «El principio de realidad, expulsado del Templo por la puerta, ha vuelto a entrar, bajo el nombre de Voluntad de Dios, por la ventana» ${ }^{12}$.

Esto nos remite a la tensión irresoluble entre el hombre profano o utilitario y el hombre sagrado o soberano, descrita por Bataille. La humanidad, dice Bataille, no puede ser definida como un estado, sino como un proceso interminable. Y ese proceso está animado por un doble y contradictorio movimiento. Por un lado, el ser humano se afirma a sí mismo como un sujeto frente al objeto, como un sujeto frente a otros sujetos y como un «nosotros» frente a «los otros», es decir, por un triple movimiento de negación o de separación (con respecto al resto de los seres, pero también con respecto a sí mismo, a su propia animalidad inocente o preconsciente). Esto es lo que le permite constituirse como sujeto laborante, 
parental y político, en una palabra, como ser profano. Pero aquello que ha sido negado por el ser profano no puede dejar de retornar a él una y otra vez. No retorna la animalidad en cuanto tal, sino una animalidad transfigurada, divinizada. En efecto, el ser humano no puede dejar de sentirse arrastrado o impulsado por un movimiento de dirección contraria, que le lleva a negarse a sí mismo, en cuanto subjetividad separada y segura de sí, y a cultivar una segunda forma de relación con el resto de los seres (y con su propio cuerpo), caracterizada por el contacto, la participación, la comunicación sagrada con ellos ${ }^{13}$.

Este doble movimiento, por el que el ser humano se afirma a sí mismo separándose del resto de los seres y se niega a sí mismo comunicándose con ellos, es lo que explica la esencial ambivalencia de lo sagrado. Lo sagrado es a un tiempo lo que aterroriza y lo que fascina, lo que amenaza con destruir el mundo de la racionalidad profana y lo que permite al hombre trascender ese mundo, superarlo o relativizarlo. Por eso, la relación con lo sagrado exige toda una serie de reglas que limiten su aparición y a un tiempo la hagan posible. Estas reglas conciernen al modo de relacionarse con los animales, con las plantas, con los fenómenos físicos, con los objetos fabricados, con el propio cuerpo y sus manifestaciones fisiológicas, con las enfermedades, con los sueños, con el nacimiento, con la muerte, con las otras personas, con los sucesos imprevistos o extraordinarios. Todo ser y todo acaecer puede devenir sagrado (y, por tanto, benéfico o maléfico), y los humanos queremos saber exactamente qué o quién, cuándo y dónde, por qué y para qué.

Ahora bien, esto no quiere decir que el campo de lo sagrado (con las reglas y relaciones que lo constituyen) se añada sin más al campo de lo profano (es decir, al triple campo de la economía, el parentesco y la política) todo acaecer tiene una doble faz, profana y sagrada, y toda relación con él adquiere esta misma ambivalencia. Por tanto, más que hablar de unas relaciones específicamente religiosas, tendríamos que hablar de la dimensión religiosa con la que se invisten todas las reglas y relaciones sociales (económicas, parentales y políticas). De hecho, la religión no sería sino el modo en que se componen entre sí lo sagrado y lo profano, en una sociedad determinada. Y a las diferentes sociedades les corresponderían formas religiosas igualmente diferentes.

En resumen, la religión puede ser considerada como una dimensión universal de la vida humana, siempre y cuando la consideremos no como una cuarta forma de relación social (junto al trabajo, el parentesco y la política), sino como aquello que articula esas tres dimensiones profanas de la vida humana, las invierte y las inviste con un sentido sagrado. La 
religión tendría, pues, una triple e inseparable función en toda cultura: la función de inversión de lo profano, la función de conjunción entre lo profano y lo sagrado, y, como consecuencia de lo anterior, la función de componer el mundo y de orientar al ser humano en él.

Ahora bien, puesto que la economía, el parentesco y la política se han venido articulando entre sí de muy diferentes maneras según los tiempos y los lugares, y puesto que esas diferentes articulaciones han dado origen a cuatro diferentes tipos históricos de sociedad (tribal, estamental, capitalista y global), no es de extrañar que cada uno de estos tipos de sociedad haya contado también con un tipo particular de religión o de universo simbólico.

En efecto, creo que es posible hablar de cuatro grandes tipos de religión: las religiones mitológicas, propias de las sociedades tribales; las religiones teológicas, que surgen con las sociedades estamentales; la religión tecnológica, que ha servido de legitimación a la moderna sociedad capitalista; y, por último, la religión ecológica, que puede llegar a convertirse en el nuevo universo simbólico de la naciente sociedad global. Pero estos cuatro tipos de religión no se sustituyen unos a otros, sino que más bien se superponen y se entretejen unos con otros.

Así, la aparición de las religiones teológicas, habitualmente llamadas «religiones de salvación», «religiones universales» o «religiones» a secas, no hizo que desaparecieran sin más las religiones mitológicas, sino que éstas fueron reorganizadas por aquéllas, produciéndose entre ambas todo tipo de sincretismos. De manera análoga, la aparición de la moderna religión tecnológica en la Europa judeo-cristiana, y su posterior expansión al resto del mundo, no significó la desaparición de las grandes religiones teológicas, sino que éstas se vieron obligadas a reorganizarse y a combinarse de uno u otro modo con aquélla. De hecho, la religión tecnológica surgió del seno mismo de la religión judeo-cristiana, y ambas se expandieron juntas a medida que Europa extendía sus colonias por el resto del mundo. Finalmente, la religión ecológica ha surgido del propio interior de la religión tecnológica, como una especie de herejía renovadora y autocrítica, y al mismo tiempo ha retomado y reelaborado algunos aspectos de las religiones mitológicas y teológicas precedentes.

Se equivocan, pues, quienes creen que el siglo XXI se va a caracterizar por una «guerra de culturas» o un «choque de civilizaciones» entre el mundo judeo-cristiano y el mundo árabe-musulmán, es decir, entre dos diferentes tipos de religión teológica, como si aún estuviéramos en la época de las cruzadas. El verdadero conflicto religioso de nuestro tiempo es el que enfrenta a la moderna religión tecnológica, hasta ahora imperante, y a la posmoderna religión ecológica, que ha surgido en las últimas dé- 
cadas y que -si sigue el actual proceso de cambio social: crecimiento demográfico, desigualdad Norte-Sur, migraciones masivas, emancipaciòn de las mujeres, multiplicación de los riesgos tecnológicamente inducidos, mundialización de las comunicaciones y de todas las relaciones socialespuede llegar a convertirse en la nueva religión de la humanidad ${ }^{14}$.

\section{Notas}

${ }^{1}$ Las ideas que expongo en este artículo las he desarrollado mucho más ampliamente en mi libro Variaciones de la vida humana. Una teoría de la historia, Akal, Madrid, 2001.

2 Max Weber, Ensayos de sociología de la religión, 2 vols., Taurus, Madrid, 1987; Economía y sociedad, FCE, México, 1964.

3 Émile Durkheim, Las formas elementales de la vida religiosa, Alianza, Madrid, 1993; Marcel Mauss, Sociología y Antropología, Tecnos, Madrid, 1971; Claude LÉviSTRAUSS, El totemismo en la actualidad, FCE, México, 1965; El pensamiento salvaje, FCE, México, 1964; Mitológicas, 4 vols., FCE, México, 1968ss.

4 Louis Dumont, Homo aequalis. Génesis y apogeo de la ideología económica, Taurus, Madrid, 1982, y Ensayos sobre el individualismo. Una perspectiva antropológica sobre la ideología moderna, Alianza, Madrid, 1987; Karl Löwith, El sentido de la historia. Implicaciones teológicas de la filosofía de la historia, Aguilar, Madrid, 1973; DAvid F. NoBLE, La religión de la tecnología. La divinidad del hombre y el espiritu de invención, Paidós, Barcelona, 1999.

5 Rafael Díaz-Salazar, Salvador Giner y Fernando Velasco (eds.), Formas modernas de religión, Alianza, Madrid, 1994.

6 Rafael SÁnchez Ferlosio, Mientras no cambien los dioses, nada ha cambiado, Alianza, Madrid, 1986.

7 Agustín García Calvo, "Sobre la realidad, o de las dificultades de ser ateo", en $L a$ lia. Ensayos de estudio lingüístico de la sociedad, Madrid, Siglo XXI, 1973 (reeditado en La venta del alma, Ediciones Libertarias, Madrid, 1980, pp.13-50); De Dios, Lucina, Madrid, 1996.

8 Thomas LuCKManN, La religión invisible, Sígueme, Salamanca, 1973.

9 Peter L. Berger y Thomas Luckmann, La construcción social de la realidad, Amorrortu, Buenos Aires, 1972.

10 Gustavo Bueno, El animal divino. Ensayo de una filosofía materialista de la religión, Pentalfa, Oviedo, 1985, p. 230.

11 Georges Bataille, Teoría de la religión, Taurus, Madrid, 1975.

12 Rafael SÁnchez Ferlosio, "O Religión o historia», en El urogallo, 8, diciembre 1986, pp. 43-58.

13 Georges Bataille, Teoría de la religión, o.c.; Lo que entiendo por soberanía, Paidós, Barcelona, 1996, pp. 63-87; ANTONIo CAMPILlo, Contra la Economía. Ensayos sobre Bataille, Comares, Granada, 2001.

14 Escribo estas últimas líneas pocos días después del 11 de septiembre de 2001, fecha del ataque suicida lanzado por un grupo de diecinueve terroristas islámicos -mediante el secuestro de cuatro aviones de pasajeros, uno de ellos estrellado cerca de Pittsburgh, antes de alcanzar su objetivo- contra las Torres Gemelas de Nueva York y contra 
el Pentágono de Washington, símbolos respectivos del poder económico y militar de la primera potencia mundial. En respuesta a este ataque brutal y espectacular, que ha causado miles de muertos y que ha sido visualizado en directo por millones de espectadores de todo el mundo, el gobierno de Estados Unidos ha solicitado la cooperación internacional, el apoyo militar de la OTAN y el amparo jurídico de la ONU, y al mismo tiempo ha puesto en marcha una gran operación antiterrorista denominada Justicia Infinita (y rebautizada luego como Libertad Duradera). Muchos comentaristas (tanto occidentales como orientales) han querido ver aquí un combate cultural y religioso entre el Occidente judeocristiano y el Oriente árabe-musulmán. En mi opinión, es un episodio más en la quiebra progresiva de la religión tecnológica, que hoy día tiene su máxima expresión en el prepotente poderío militar, económico y mediático de Estados Unidos. Bruscamente, los norteamericanos han descubierto la extrema vulnerabilidad de ese poderío, la necesidad de contar con la ayuda de todos los Estados del mundo y los compromisos internacionales a los que esa ayuda les obliga. Pero lo que está socavando desde hace tiempo la creencia en la invulnerabilidad del poderío estadounidense $-\mathrm{y}$ en la religión tecnológica que le sirve de sustento- no son los grupos terroristas islámicos, defensores de una religión teológica premoderna que se resiste a modernizarse, sino las numerosas organizaciones civiles "no gubernamentales" $\mathrm{y}$ "sin fronteras" que han proliferado en todo el mundo durante las tres últimas décadas. Estas formas post modernas de fraternidad religiosa están luchando -de manera pacífica pero muy activa- no contra la "globalización", como suele decirse, sino todo lo contrario: por una verdadera civilización global, fundada en los nuevos valores sagrados del cosmopolitismo ecológico. 